\title{
Relação entre macrófagos espumosos ("foam cells") no fígado de bovinos e ingestão de Brachiaria spp no Brasil ${ }^{1}$
}

\author{
David Driemeier $^{2}$, Jürgen Döbereiner ${ }^{3}$, Paulo Vargas Peixoto ${ }^{4}$ e Marilene F. Brito ${ }^{5}$
}

\begin{abstract}
Driemeier D., Döbereiner J., Peixoto P.V. \& Brito M.F. 1999. [Relationship between foamy macrophages in the liver of cattle and the ingestion of Brachiaria spp.] Relação entre macrófagos espumosos ("foam cells") no figado de bovinos e ingestão de Brachiaria spp no Brasil. Pesquisa Veterinária Brasileira 19(2):79-83. Depto Patologia Clínica Veterinária, Faculdade de Veterinária, UFRGS, Cx. Postal 15094, Porto Alegre, RS 91540-000, Brazil.

To establish the etiological relationship and the appearance of foamy macrophages in the liver of cattle from tropical regions of Brazil, liver samples from the files of the Pathology Section of Embrapa-Projeto Sanidade Animal, Rio de Janeiro, were reviewed. A total of 55 liver samples of cattle which died from different causes between 1970 and 1991 were reexamined. Only samples of animals which grazed known pastures were reviewed. Foamy macrophages were not seen in the samples from 1970 to 1975 , although 40 samples $(72 \%)$ were from this period. Foamy macrophages were observed from 1976 on, coinciding with the introduction of Brachiaria decumbens from Australian seeds into Brazil. Some samples were from cattle with histories of photosensitization, which were at that time attributed to Pithomyces chartarum. The results of this study indicate that the liver changes are related to prolonged ingestion of Brachiaria spp.
\end{abstract}

INDEX TERMS: Brachiaria decumbens, B. humidicola, foamy macrophages (foam cells), cattle.

RESUMO.- Com o objetivo de estabelecer uma relação etiológica e caracterizar, cronologicamente, o aparecimento de macrófagos espumosos (foam cells), comuns em fígados de bovinos oriundos das regiões de clima tropical do Brasil, foram reexaminados cortes histológicos de fígado de bovinos dos arquivos do Setor de Anatomia Patológica da EmbrapaProjeto Sanidade Animal, RJ. O material utilizado provinha de investigações sobre causas de mortandades em bovinos nas regiões Norte, Centro-Oeste e Sudeste do Brasil, realizadas de 1970 a 1991 . Foram estudados 55 fígados de bovinos afetados por enfermidades variadas. Somente foram usados

\footnotetext{
${ }^{1}$ Aceito para publicação em 6 de julho de 1998.

${ }^{2}$ Depto Patologia Clínica Veterinária, Fac. Vet UFRGS, Cx. Postal 15094, Porto Alegre, RS 91540-000, E-mail: Davetpat@vortex.ufrgs.br. Fax 0513191513; bolsista do CNPq (301076/93-6). Autor para correspondência.

${ }^{3}$ Embrapa-CNPAB/PSA, Km 47, Seropédica, RJ 23851-970; bolsista do CNPq (305294/88-1).

${ }^{4}$ Depto Epidemiologia e Saúde Pública, Universidade Federal Rural do Rio de Janeiro (UFRRJ) , Seropédica, RJ 23851-970; bolsista do CNPq (302342/869).

${ }^{5}$ Depto Epidemiologia e Saúde Pública, Setor de Anatomia Patológica, UFRRJ.
}

casos em que o tipo de pastagem era conhecido. Essa alteração não foi encontrada de 1970 até o final de 1975, embora 40 amostras $(72,7 \%)$ tenham sido coletadas nesse período. A presença de macrófagos espumosos, observada a partir de 1976, coincidiu com a introdução da gramínea Brachiaria decumbens var. australiana no Brasil. Algumas amostras eram provenientes de bovinos que apresentaram histórico de fotossensibilização, na época atribuída ao fungo Pithomyces chartarum. Os achados indicam que essas alterações hepáticas são relacionadas com a ingestão de Brachiaria spp.

TERMOS DE INDEXAÇÃO: Brachiaria decumbens, B. humidicola, células espumosas, alterações hepáticas, bovinos.

\section{INTRODUÇÃO}

Em 1972, a gramínea Brachiaria decumbens var. australiana foi introduzida no Brasil. A sua propagação, na formação de pastagens, se dava através das sementes, enquanto que a difusão da variedade anterior, já existente no país nessa época, introduzida pelo IPEAN (Inst. Pesq. Agropecuária do Norte, Belém) antes de 1972, era feita somente através de mudas (Hutton 1975, Nazário et al. 1977). Após a disseminação de $B$. decumbens, pelas sementes, surgiram inúmeros surtos de fotossensibilização em bovinos, a ponto de discutir-se sua 
viabilidade no país, diante dos prejuízos que causava (Anônimo 1977). A fácil difusão e a alta capacidade de produção de massa verde em solos pobres, tornou essa gramínea de grande importância econômica para a pecuária brasileira, suplantando a desvantagem de causar fotossensibilização em ruminantes no cerrado (Fagliari et al. 1983). Em função do descrito na literatura, essas mortes foram atribuídas, na época, à presença do fungo Pithomyces chartarum (Amaral et al 1976). Entre os numerosos trabalhos que em seguida foram publicados sobre o assunto, especialmente envolvendo aspectos patológicos e epidemiológicos, se destacam os de Fagliari et al. (1993) e Alessi et al. (1994). Em todas as descrições de fotossensibilização no Brasil, os autores são unânimes em atribuir as lesões cutâneas a lesões hepáticas (fotossensibilização hepatógena).

Peixoto \& Tokarnia (1983) observaram grande quantidade de macrófagos espumosos no fígado de uma búfala, proveniente de um rebanho mantido em pastagem de Brachiaria humidicola, no qual ocorreram diversos casos de fotossensiblização; apesar de levantarem a hipótese de que essas lesões eram provocadas pela própria Brachiaria, uma vez que diferiam das provocadas por Pithomyces chartarum, não a comprovaram.

Leme et al. (1988) verificaram essas células espumosas no fígado de bovinos e Lemos et al. (1996) as observaram no
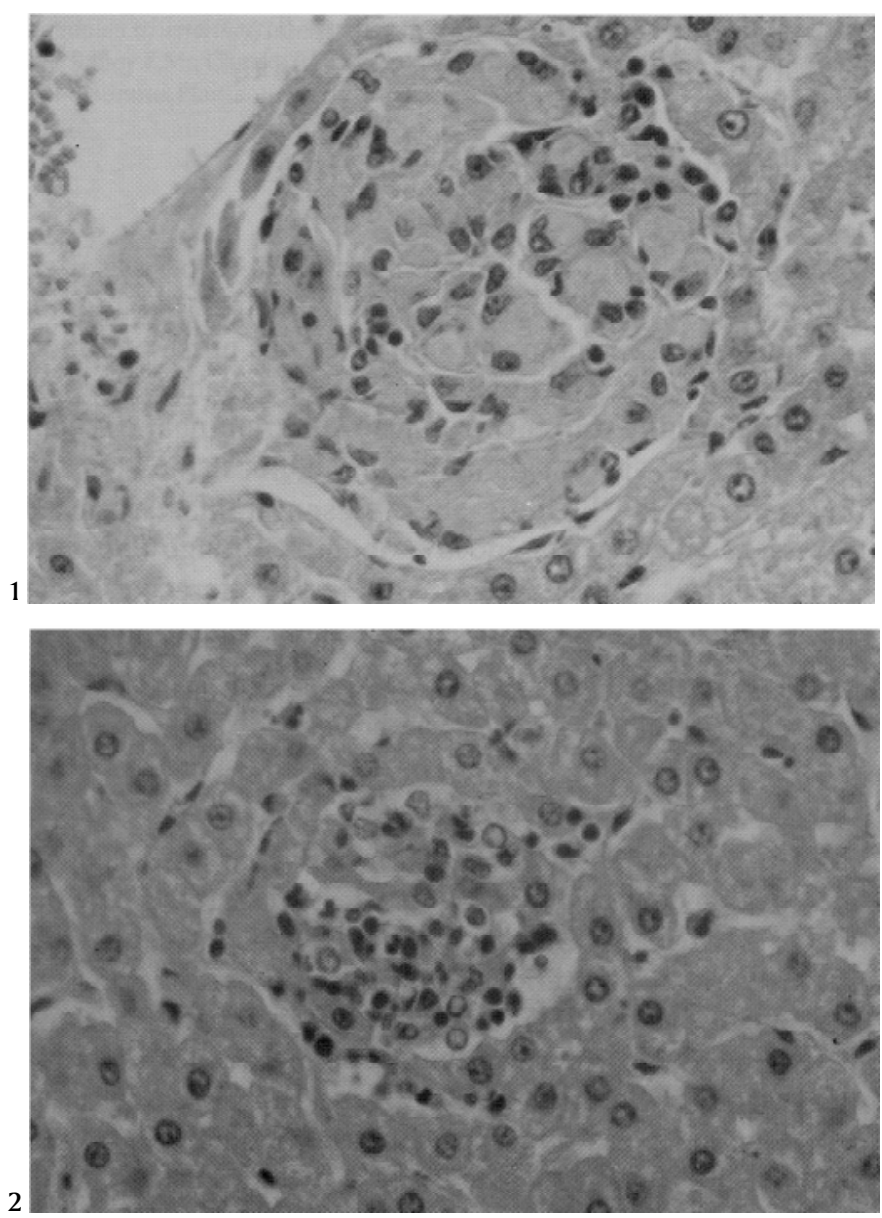

fígado de ovinos e, em ambos os casos, associaram sua presença à ingestão de Brachiaria decumbens. Silva (1989) também descreveu estas alterações, entretanto, supôs que estavam associadas à "cara inchada" dos bezerros; $52,2 \%$ dos animais estudados com essa enfermidade apresentavam os referidos macrófagos no fígado. No estudo ultramicroscópico, esse autor demonstrou estruturas com imagem negativa, de contorno semelhante a cristais revestidos por membrana, assemelhando-se a fagolisossomos, no citoplasma dos macrófagos.

O objetivo desse trabalho foi o de verificar, cronologicamente, uma possível relação entre o aparecimento de células com citoplasma espumoso com a introdução de $B$. decumbens no Brasil e ratificar, através de reexame de material de arquivo, essa gramínea como causa dessa alteração.

\section{MATERIAL E MÉTODOS}

Foram reexaminadas 55 amostras de fígado de bovinos retirados dos arquivos do Setor de Anatomia Patológica (SAP) da EmbrapaSanidade Animal, Km 47, Seropédica, RJ. O material provinha de investigações sobre causas de mortandades em bovinos nas regiões Norte, Centro-Oeste e Sudeste do Brasil, realizadas de 1970 a 1991. Estas amostras foram coletadas em bovinos que morreram ou foram sacrificados, afetados por diversas enfermidades. Os dados sobre os animais foram obtidos dos cadernos de registros das viagens de estudos da equipe técnica do Setor de Anatomia Patológica da Embrapa-Sanidade Animal, efetuados nessas regiões. As lâminas dos casos estudados, coradas com hematoxilina-eosina (HE), foram novamente avaliadas quanto à presença de células espumosas.

Fig. 1. Fígado com macrófagos de citoplasma espumoso formando um foco próximo a veia centrolobular (Bov. 3873). HE, obj. 40.

Fig. 2. Infiltrado focal de células mononucleares e alguns neutrófilos no fígado, possivelmente representando as fases iniciais de formação dos focos de macrófagos espumosos (Bov. 4658). HE, obj. 25.

Fig. 3. Macrófagos com citoplasma espumoso presentes no fígado, apresentando estruturas com imagem negativa de cristais semelhantes a fendas de colesterol (Bov. 4664). HE, obj. 100.




Quadro 1. Dados epidemiológicos dos bovinos utilizados no estudo sobre macrófagos espumoso ("foam cells") no fígado, no Brasil

\begin{tabular}{|c|c|c|c|c|c|c|c|c|c|}
\hline $\begin{array}{l}\text { No. de } \\
\text { ordem }\end{array}$ & $\begin{array}{c}\text { Bovino } \\
\text { no. }\end{array}$ & Sexo & Idade ‘ & $\begin{array}{l}\text { "Foam } \\
\text { cells" }\end{array}$ & $\begin{array}{c}\text { Morte } \\
\text { (forma) }\end{array}$ & $\begin{array}{c}\text { Data da } \\
\text { coleta }\end{array}$ & $\begin{array}{c}\text { Procedência } \\
\text { (Município, Estado) }\end{array}$ & Pastagem & Diagnóstico clínico-patológico \\
\hline 1 & 2817 & $\mathrm{~m}$ & 2 anos & $-\mathrm{a}$ & Sacrif. & 05.07.70 & Pantanal Corumbá, MS & Natural & Verminose, Intoxicação por Solanum malacoxylon, incipiente \\
\hline 2 & 2818 & $\mathrm{f}$ & 4 anos & - & Sacrif. & 06.07 .70 & Pantanal Corumbá, MS & Natural & Intoxicação por S. malacoxylon, moderada \\
\hline 3 & 2819 & f & 4 anos & - & Sacrif. & 07.07 .70 & Pantanal Corumbá, MS & Natural & Intoxicação por S. malacoxylon, acentuada \\
\hline 4 & 2821 & $\mathrm{~m}$ & 4 anos & - & Sacrif. & 11.07 .70 & Pantanal Poconé, MT & Natural & Intoxicação por Ipomea fistulosa \\
\hline 5 & 2822 & $\mathrm{f}$ & 30 meses & - & Sacrif. & 14.07 .70 & Poconé, MT & Natural & Intoxicação por $S$. malacoxylon, em recuperação \\
\hline 6 & 2823 & $\mathrm{~m}$ & 2 anos & - & Sacrif. & 14.07 .70 & Poconé, MT & Natural & Intoxicação por S. malacoxylon, moderada \\
\hline 7 & 2825 & $\mathrm{f}$ & 6 anos & - & Sacrif. & 17.07.70 & Barra do Bugres, MT & Colonião & "Cara inchada" \\
\hline 8 & 2826 & $\mathrm{~m}$ & 18 meses & - & Sacrif. & 18.07 .70 & Barra do Bugres, MT & Colonião & Deficiência de cobalto \\
\hline 9 & 2827 & $\mathrm{f}$ & 3 anos & - & Sacrif. & 21.07.70 & Chapada dos Guimarães, MT & Natural & Deficiência de cobalto \\
\hline 10 & 2828 & $\mathrm{f}$ & 6 anos & - & Sacrif. & 22.07 .70 & Mineiros, GO & Colonião & Deficiência de cobalto, fígado com esteatose \\
\hline 11 & 3320 & $\mathrm{~m}$ & 4 anos & - & Sacrif. & 06.04 .72 & Poconé, MT & Natural & Intoxicação por $S$. malacoxylon, verminose gastrintestinal \\
\hline 12 & 3324 & $\mathrm{~m}$ & 4 anos & - & Sacrif. & 05.04 .72 & Barra do Bugres, MT & Colonião & Deficiências de cobalto e cobre \\
\hline 13 & 3325 & m & 4 anos & - & Sacrif. & 09.04 .72 & Barra do Bugres, MT & Colonião & Deficiência de cobalto \\
\hline 14 & 3327 & $\mathrm{f}$ & 1 ano & - & Sacrif. & 11.04 .72 & Rondonópolis, MT & Colonião & "Cara inchada" \\
\hline 15 & 3330 & $\mathrm{~m}$ & 5 anos & - & Sacrif. & 15.04 .72 & Torixoréo, MT & Colonião & Deficiências de cobalto e cobre \\
\hline 16 & 3331 & $\mathrm{f}$ & 7 anos & - & Sacrif. & 15.04 .72 & Torixoréo, MT & Colonião & "Cara inchada" \\
\hline 17 & 3332 & $\mathrm{f}$ & 4 anos & - & Sacrif. & 18.04 .72 & Barra do Bugres, MT & Colonião & Deficiência de cobalto, esteatose hepática \\
\hline 18 & 3333 & $\mathrm{~m}$ & 18 meses & - & Sacrif. & 18.04 .72 & Barra do Bugres, MT & Colonião & "Cara inchada" curada \\
\hline 19 & 3335 & $\mathrm{f}$ & 5 anos & - & Sacrif. & 19.04 .72 & Barra do Bugres, MT & Colonião & "Cara inchada" \\
\hline 20 & 3413 & $\mathrm{f}$ & 30 meses & - & Sacrif. & 30.09 .72 & Rondonópolis, MT & Colonião & "Cara inchada" \\
\hline 21 & 3415 & $\mathrm{~m}$ & 22 meses & - & Sacrif. & 02.10 .72 & Rondonópolis, MT & Colonião & "Cara inchada" \\
\hline 22 & 3417 & $\mathrm{f}$ & 4 anos & - & Sacrif. & 04.10 .72 & Rondonópolis, MT & Colonião & "Cara inchada" \\
\hline 23 & 3418 & $\mathrm{~m}$ & 14 meses & - & Sacrif. & 05.10 .72 & Rondonópolis, MT & Colonião & "Cara inchada" \\
\hline 24 & 3419 & $\mathrm{~m}$ & 1 ano & - & Sacrif. & 05.10 .72 & Rondonópolis, MT & Colonião & "Cara inchada" \\
\hline 25 & 3420 & $\mathrm{f}$ & 28 meses & - & Sacrif. & 06.10 .72 & Poxoréo, MT & Colonião & "Cara inchada" \\
\hline 26 & 3421 & f & 5 anos & - & Sacrif. & 07.10 .72 & Rondonópolis, MT & Colonião & "Cara inchada" curada e subdeficência de cobre \\
\hline 27 & 3422 & $\mathrm{f}$ & 15 anos & - & Sacrif. & 07.10 .72 & Rondonópolis, MT & Colonião & Subdeficiência de cobre \\
\hline 28 & 3423 & f & 6 anos & - & Sacrif. & 07.10 .72 & Rondonópolis, MT & Colonião & Deficiência de cobre \\
\hline 29 & 3425 & $\mathrm{~m}$ & 30 meses & - & Sacrif. & 09.10 .72 & Rondonópolis, MT & Colonião & "Cara inchada" \\
\hline 30 & 3440 & $\mathrm{f}$ & 4 anos & - & Sacrif. & 22.03 .72 & Poconé, MT & Natural & Intoxicação por S. malacoxylon \\
\hline 31 & 3719 & $\mathrm{~m}$ & 7 meses & - & Sacrif. & 03.07 .74 & Pires do Rio, GO & $\begin{array}{l}\text { Colonião/ } \\
\text { natural }\end{array}$ & "Cara inchada" \\
\hline 32 & 3721 & $\mathrm{~m}$ & 30 meses & - & Sacrif. & 04.07.74 & Pires do Rio, GO & $\begin{array}{l}\text { Colonião/ } \\
\text { natural }\end{array}$ & "Cara inchada" \\
\hline 33 & 3730 & $\mathrm{~m}$ & 10 meses & - & Sacrif. & 01.08 .74 & Rondonópolis, MT & Colonião & "Cara inchada" e deficiência de cobre \\
\hline 34 & 3731 & $\mathrm{f}$ & 10 meses & - & Sacrif. & 01.08 .74 & Rondonópolis, MT & Colonião & "Cara inchada" \\
\hline 35 & 3732 & f & 10 meses & - & Sacrif. & 01.08 .74 & Rondonópolis, MT & Colonião & "Cara inchada" \\
\hline 36 & 3733 & $\mathrm{~m}$ & 3 meses & - & Sacrif. & 01.08 .74 & Rondonópolis, MT & Colonião & "Cara inchada" \\
\hline 37 & 3744 & $\mathrm{~m}$ & 9 meses & - & Sacrif. & 17.02 .75 & Itiquira, MT & Natural & "Cara inchada" curada \\
\hline 38 & 3745 & $\mathrm{~m}$ & 1 ano & - & Sacrif. & 17.02.75 & Itiquira, MT & Natural & "Cara inchada" \\
\hline 39 & 3746 & $\mathrm{~m}$ & 8 meses & - & Sacrif. & 17.02.75 & Itiquira, MT & Natural & "Cara inchada" curada \\
\hline 40 & 3747 & $\mathrm{~m}$ & 9 meses & - & Sacrif. & 17.02 .75 & Itiquira, MT & Natural & "Cara inchada" curada \\
\hline 41 & 3805 & $\mathrm{f}$ & 18 meses & - & Sacrif. & 26.05 .76 & Xapurí, AC & $\begin{array}{l}\text { Colonião/ } \\
\text { natural }\end{array}$ & Intoxicação por Palicourea marcgravii \\
\hline 42 & 3806 & $\mathrm{f}$ & 2 anos & - & Sacrif. & 29.05 .76 & Xapurí, AC & $\begin{array}{l}\text { Jaraguá/ } \\
\text { colonião }\end{array}$ & "Cara inchada" \\
\hline 43 & 3807 & $\mathrm{f}$ & 9 meses & - & Sacrif. & 29.05 .76 & Rio Branco, AC & $\begin{array}{l}\text { Jaraguá/ } \\
\text { colonião }\end{array}$ & "Cara inchada" \\
\hline 44 & 3815 & $\mathrm{f}$ & 14 meses & + & Sacrif. & 01.08 .76 & Sto Ant ${ }^{\circ}$. do Leverger, MT & $\begin{array}{l}\text { Brachiaria } \\
\text { decumbens }\end{array}$ & Lesões de fotossensibilização, em cura \\
\hline 45 & 3862 & $\mathrm{~m}$ & 8 meses & - & Sacrif. & 03.10 .78 & Rondonópolis, MT & Colonião & "Cara inchada" \\
\hline 46 & 3863 & $\mathrm{~m}$ & 8 meses & - & Sacrif. & 03.10 .78 & Rondonópolis, MT & Colonião & "Cara inchada" \\
\hline 47 & 3872 & $\mathrm{f}$ & Adulta & ++ & Natural & 22.03 .79 & Cassilândia, MS & $\begin{array}{l}\text { Pasto misto/ } \\
\text { Brachiaria spp }\end{array}$ & Botulismo \\
\hline 48 & 3873 & f & 5 anos & +++ & Sacrif. & 18.10 .79 & Rondonópolis, MT & $\begin{array}{l}\text { Brachiaria spp/ } \\
\text { colonião }\end{array}$ & "Cara inchada" e subdeficiência de cobre \\
\hline 49 & 4628 & $\mathrm{f}$ & 4 anos & ++ & Natural & 21.01 .87 & Rancharia, SP & $\begin{array}{l}\text { Brachiaria } \\
\text { decumbens }\end{array}$ & Botulismo \\
\hline 50 & 4519 & $\mathrm{f}$ & 6 anos & ++ & Sacrif. & 28.06 .80 & Nobres, MT & Brachiaria spp & "Cara inchada" \\
\hline 51 & 4658 & $\mathrm{~m}$ & 1 ano & + & Sacrif. & 14.06 .88 & Luiz Antônio, SP & Brachiaria spp & Verminose gastrintestinal \\
\hline 52 & 4659 & $\mathrm{f}$ & 3 anos & ++ & Sacrif. & 14.06 .88 & São Simão, SP & Brachiaria spp & Hemoncose \\
\hline 53 & 4664 & $\mathrm{f}$ & 30 meses & + & Sacrif. & 04.01 .91 & José Bonifácio, SP & $\begin{array}{l}\text { Brachiaria } \\
\text { humidicola }\end{array}$ & Botulismo \\
\hline 54 & 4668 & $\mathrm{f}$ & 3 anos & ++ & Natural & 21.02 .91 & Uberaba, MG & $\begin{array}{l}\text { Brachiaria } \\
\text { decumbens }\end{array}$ & Botulismo \\
\hline 55 & 4670 & $\mathrm{f}$ & 3 anos & + & Sacrif. & 01.05 .91 & Sales, SP & $\begin{array}{l}\text { Brachiaria } \\
\text { decumbens }\end{array}$ & Deficiência de cobalto \\
\hline
\end{tabular}

a +++ Lesão acentuada, ++ moderada, + leve, - ausente. 


\section{RESULTADOS}

Os resultados estão resumidos no Quadro 1. Os fragmentos de fígado examinados eram provenientes de bovinos mantidos em diversos tipos de pastagem, que apresentaram as seguintes doenças: botulismo, "cara inchada" (periodontite) dos bezerros, verminose gastrintestinal, intoxicações por Solanum malacoxylon ("espichamento"), Ipomoea fistulosa e Palicourea marcgravii, e deficiências de cobalto e de cobre. Os diagnósticos das enfermidades basearam-se principalmente em achados epidemiológicos, clínicos, de necropsia, histopatológicos e análises químicas.

No exame histológico não se observaram macrófagos espumosos nas 40 amostras de fígado coletadas no período compreendido entre 1970 e 1975 . A partir de 1976, porém, observaram-se os primeiros casos em que havia presença de macrófagos com citoplasma espumoso ("foam cells") no fígado dos bovinos. Quando isoladas, estas células eram difíceis de distinguir de hepatócitos adjacentes, porém eram bem reconhecíveis quando formavam aglomerados, mais frequentes ao redor das veias centrolobulares (Fig.1). Por vezes, as células espumosas formavam células multinucleadas. Em alguns focos com macrófagos de citoplasma pouco evidente, às vezes associados com alguns linfócitos (Fig. 2), havia presença de neutrófilos em meio a restos de hepatócitos necróticos. Quando observados com objetiva de imersão, os macrófagos espumosos, por vezes, apresentavam estruturas com imagens negativas de cristais, semelhantes a fendas de colesterol (Fig. 3). A intensidade das alterações relativas às células espumosas variava de leve a moderada. Em um caso, as alterações foram consideradas acentuadas $\left(\mathrm{N}^{\circ} 48\right.$, Bov. 3873); neste mesmo caso, o baço também foi examinado e apresentava o mesmo tipo de macrófagos.

\section{DISCUSSÃO}

O aparecimento dos macrófagos espumosos no fígado de bovinos, coletados a partir de 1976, coincide com a introdução de Brachiaria spp como pastagem principal. Pela revisão do material de arquivo, verifica-se que macrófagos de citoplasma espumoso não estavam presentes em bovinos que não ingeriram Brachiaria sp, o que indica a relação entre a sua presença e a ingestão da planta.

Entretanto, a relação dessas células com a fotossensibilização não está bem estabelecida. Döbereiner et al. (1976) e Alessi et al. (1994) não descreveram a presença de macrófagos espumosos em surtos de fotossensibilização cujos animais pastavam em Brachiaria decumbens. Nesse caso, sugerese que para o aparecimento dessas células, é necessário um longo período de ingestão de Brachiaria spp. De fato, ovinos alimentados durante 77 dias exclusivamente com Brachiaria decumbens com baixa contagem de esporos de P. chartarum, não demonstraram fotossensibilização e, após sacrifício ao fim desse período, não apresentaram macrófagos espumosos no fígado, embora tivessem apresentado colangiopatia com acúmulo de cristais em ductos biliares (Driemeier et al. 1997). De outros 5 ovinos mantidos em pastagem de $B$. decumbens, um apresentou fotossensibilização após 70 dias e foi sacrifi- cado. No exame do fígado desse animal, verificaram-se colangite e presença de cristais nas vias biliares, mas não havia macrófagos espumosos. Os outros 4 ovinos pastaram exclusivamente $B$. decumbens durante 150 dias e não mostraram sintomas de fotossensibilização; entretanto, após sacrifício, ao exame histopatológico foi constatada a presença de macrófagos espumosos no fígado e em linfonodos, além de leve a moderada colangite com presença de cristais nas vias biliares (Driemeier et. al. 1998). Silva (1989) observou a presença incipiente de células espumosas no fígado de bovinos com 5 a 8 meses de idade, que apresentaram "cara inchada" e, provavelmente, eram mantidos em pastagem de Brachiaria sp, sem sintomas de fotossensibilização. Nos animais mais velhos essas alterações eram mais acentuadas. Há, possivelmente, uma relação entre macrófagos espumosos e graus variados de obstrução biliar. As lesões dos ductos biliares poderiam ser resultantes da eliminação de substâncias tóxicas pela alimentação com Brachiaria spp, sejam estas atribuídas à esporidesmina produzida por $P$. chartarum (Alessi et al. 1994) ou à composição do próprio capim. Graydon et al. (1991) e Driemeier et al. (1997) verificaram, em ovinos alimentados com $B$. decumbens com baixa contagem de esporos de $P$. chartarum, a presença de estruturas cristalóides nos ductos biliares. Segundo Patrick (1983), em humanos as patologias biliares que causam obstrução de ductos biliares cursam frequentemente com coleções de macrófagos com ou sem formação de células multinucleadas no parênquima hepático.

A presença de esporidesmina não tem sido confirmada em muitos surtos de fotossensibilização no Brasil (Lemos et al. 1996, Meagher et al. 1996). O achado de estruturas com imagem negativa de cristais semelhantes a fendas de colesterol, só visíveis em aumentos maiores, representam material fagocitado por macrófagos e podem ser vistos, através da ultraestrutura, também em hepatócitos e macrófagos de bovinos sadios de abatedouro, que se alimentavam de Brachiaria spp (Driemeier et al. 1998).

\section{REFERÊNCIAS}

Alessi A.C., Fagliari, J.J., Okuda H.T. \& Passipieri M. 1994. Intoxicação natural de bovinos pela micotoxina esporidesmina. 4. Lesões hepáticas. Arq. Bras. Med. Vet. Zootec. 46 (4):319-328.

Amaral R.E., Nazario W \& Andrade S.O. 1976. Ocorrência do fungo Pithomyces chartarum (Berk. \& Curt.) M.B. Ellis em grãos e forrageiras no Brasil. IX Congr. Bras. Fitopatologia, Campinas, p.82.

Anônimo 1977. Brachiaria decumbens. Fotossensibilização em bovinos. Noticioso Rhodia-Meriéux, p. 7-9.

Döbereiner J., Tokarnia C.H, Monteiro M.C.C., Cruz L.C.H., Carvalho E.G. \& Primo A.T. 1976. Intoxicação de bovinos e ovinos em pastos de Brachiaria decumbens contaminados por Pithomyces chartarum. Pesq. Agropec. Bras., Sér. Vet. 11:87-94.

Driemeier D., Kreimeier R.D., Colodel E.M., Fries C., Seitz A.L. Oliveira R.T. \& Schmitt A.C. 1997. Colangiopatia experimental induzida por alimentação de ovinos com Brachiaria decumbens. VIII Encontro Nacional de Patologia Veterinária, 21 - 25 julho, Pirassununga, SP (Resumo PE-16).

Driemeier D., Barros S.S., Peixoto P.V., Tokarnia C.H., Döbereiner J. \& Brito M.F. 1998. Estudos histológico, histoquímico e ultraestrutural de fígados e linfonodos de bovinos com presença de macrófagos espumosos ("foam cells"). Pesq. Vet. Bras.18(1):29-34.

Fagliari J.J., Passipieri M. \& Oliveira J.A. 1983. Sintomas de fotossensibilização 
em bezerros alimentados com leite materno. Arq. Bras. Med. Vet. Zootec. 35(4): 479-484.

Fagliari J.J., Okuda H.T., Kuchembuck M.R.G. \& Curi P.R. 1993. Intoxicação natural de bovinos pela micotoxina esporidesmina. I. Aspectos epidemiológicos. Arq. Bras. Med. Vet. Zootec. 45(3): 263-274.

Graydon R.J., Hamid H., Zahari P. \& Gardiner C. 1991. Photosensitisation and crystal-associated cholangiohepatopathy in sheep grazing Brachiaria decumbens. Aust. Vet. J. 68(7):234-236.

Hutton E.M. 1975. Report on the Brachiaria decumbens problem on Fazenda São Tomás Abóboras of Carlos Cunha, Rio Verde, Goiás, visited August 15, 1975. IPB Comércio de Sementes Ltda. 3p. (Datilografado)

Leme M.C.M., Mandorino I., Macruz R. \& Campdelli Filho, O. 1988. Lesões degenerativas nodulares no fígado de bovinos mantidos em pastos de Brachiaria sp no Estado de São Paulo, Brasil. Inst. Biológico, S. Paulo, 55: 54.

Lemos R.A.A., Ferreira L.C.L., Silva S.M., Nakato L. \& Salvador S.C. 1996. Fotossensibilização e colangiopatia associada a cristais em ovinos em pastagem de Brachiaria decumbens. Ciência Rural, Santa Maria, 26:109-113.
Meagher L.P., Wilkins A.L, Miles C.O, Collin R.G.\& Fagliari J.J. 1996. Hepatogenous photosensitization of ruminants by Brachiaria decumbens and Panicum dichotomiflorum in the absence of sporidesmin: lithogenic saponins may be responsible. Vet. Hum. Toxicol. 38:271-274.

Nazário W., Amaral R.E.M., Angeli V.M., Cappellaro C.E.M.P.D.M., Fernandes N.S. \& Camargo W.V.A. 1977. Intoxicação experimental produzida pelo Pithomyces chartarum (Berk. \& Curt.) M.B. Ellis, isolado de Brachiaria decumbens. Biológico, S. Paulo, 43(5,6):125-131.

Patrick R.S. 1983. Colour Atlas of Liver Pathology. Harwey Miller, Oxford University. 174p.

Peixoto P.V. \& Tokarnia C.H. 1983. Comunicação pessoal (Univ. Fed. Rural do Rio de Janeiro).

Silva L. B. 1989. Alterações hepáticas em bovinos acometidos de doença periodontal (cara inchada). Tese de Mestrado, Universidade Federal de Minas Gerais, Belo Horizonte. 27p. 